\title{
Histologic Distribution of Pulmonary Tumors in Lebanon: A 5-Year Single Institution Experience
}

\author{
Hampig Raphael Kourie ${ }^{1}$, Marc Rassy ${ }^{2 *}$, Claude Ghorra ${ }^{2}$, Samah Naderi², \\ Joseph Kattan ${ }^{1}$
}

\begin{abstract}
Background: To compare the current histologic distribution of lung cancer in Lebanon to the worldwide trends, according to the 2004 WHO Classification. Materials and Methods: 1,760 patients with a pulmonary pathology examination at Hotel-Dieu de France University Hospital between July 2009 and July 2014 were included. Results: Some 676 out of the total investigated patients $(38.4 \%)$ had a lung tumor. In $665(98.4 \%)$ the tumors were malignant, with a mean age at diagnosis of 63.8 years and a male/female (M/F) sex ratio of 1.7:1. Among the malignant tumors, 86.2\% were epithelial tumors with a mean age at diagnosis of 64.8 years and an $\mathrm{M} / \mathrm{F}$ sex ratio of 1.9. Other malignant tumors consisted of metastatic tumors $(\mathbf{1 0 . 2 \%})$, lymphoproliferative tumors $(2.1 \%)$ and mesenchymal tumors $(\mathbf{1 . 5 \%})$. Most common carcinoma subtypes were adenocarcinoma $(\mathbf{4 8 . 0 \% ) ,}$ squamous cell carcinoma (23.0\%) and small cell carcinoma (13.3\%). Carcinoid tumors were the only carcinoma subtype with an M/F sex ratio below $1(0.7)$. Salivary gland tumors were the carcinoma with lowest mean age at diagnosis (45.5 years). Conclusions: The histologic distribution of lung tumors in Lebanon is similar to that in developed countries. We believe this resemblance is due to common smoking habits, known to be responsible for the increase of lung adenocarcinoma at the expense of other subtypes.
\end{abstract}

Keywords: Lung cancer - histologic subtypes - squamous cell carcinoma - small cell carcinoma - Lebanon

Asian Pac J Cancer Prev, 16 (14), 5899-5902

\section{Introduction}

Lung cancer is the most frequent cancer worldwide and the most common cause of cancer death among both sexes, according to the GLOBOCAN 2012 (Ferlay et al., 2015). In Lebanon, in 2008, it represented the second most frequent cancer in men and the third in women (2008). In the present study, we report, for the first time in the literature, the histologic distribution of lung cancer in Lebanon, according to the 2004 WHO Classification of Lung Tumors.

The histologic subtypes of lung cancer have a practical impact on the choice of chemotherapeutical agents in treatment of lung cancer. Adenocarcinomas beneficiate from a treatment based on Pemetrexed as the second agent in Platin-doublet and from Bevacizumab associated to Platine-doublet, while Bevacizumab is contra-indicated in squamous cell lung cancer (Scagliotti et al., 2008; Hainsworth et al., 2011).

Many recent studies are describing variations in the histologic subtypes distribution in the last decade in relation to the variation of smoking habits, lifestyle and genetics. This histologic subtype distribution varies also according to geographic differences (Spitz et al., 2011;
Yang, 2011).

The aim of this study is to report the distribution of histological subtypes of lung cancers in Lebanon and to compare to data from other countries.

\section{Materials and Methods}

A search for pulmonary specimens (biopsic, cytological and surgical) in the computerized database of the pathology department of Hotel-Dieu de France, Saint Joseph University hospital was conducted. All the pathology reports (3286 reports) evaluating specimens of pulmonary origin were collected during a period of 5 years starting from July 2009 to July 2014. One thousand, seven hundred and sixty (1760) cases were included after eliminating the duplicate cases.

The included cases were categorized into tumoral or non-tumoral, benign or malignant. Malignant tumors were sub-classified into the different histologic subtypes of malignant tumors according to the 2004 WHO classification of lung tumors. Data concerning patients' characteristics (age and sex), presence of tumor, and histological tumor subtype, were analyzed using the SPSS version 20 statistics program. 


\section{Results}

Six hundred and seventy six $(676-38.4 \%)$ out of 3286 specimens and corresponding to 1760 patient were of tumoral nature. Out of the 676 tumor cases, $11(1.6 \%)$ were benign and $665(98.4 \%)$ were malignant. The mean age of patients having malignant tumors was 63.8 years with an $\mathrm{M} / \mathrm{F}$ sex ratio of 1.7 , while the mean age of those having benign tumors was 52.9 years with an $\mathrm{M} / \mathrm{F}$ sex ratio of 2.7 .

The 665 malignant tumors were distributed as follows: epithelial tumors: $573(86.1 \%)$, mesenchymal tumors: $10(1.5 \%)$, lymphoproliferative tumors: $14(2.1 \%)$ and metastatic tumors: $68(10.2 \%)$. The mean age of patients having a primary lung carcinoma was 64.8 years (64.3 in women and 65.1 in men) with an M/F sex ratio of 1.9, while the mean age of patients having a metastatic tumor to the lungs was 60.1 years (56.0 years in women and 63.9 in men) with an $\mathrm{M} / \mathrm{F}$ sex ratio of 1.1. The mean age of patients having mesenchymal tumors was 56.5 years $(\mathrm{M} / \mathrm{F}$ sex ratio of 1.0) and of those having lymphoproliferative tumors 50.1 years $(\mathrm{M} / \mathrm{F}$ sex ratio of 0.6$)$.

Among 573 malignant epithelial tumors, 275 (48.0\%) were adenocarcinomas, $132(23.0 \%)$ squamous cell carcinomas, $76(13.3 \%)$ small cell carcinomas, 46

Table 2. Comparison of Male and Female Patients' Proportions

\begin{tabular}{lrrrrr}
\hline & Male patients & \multicolumn{3}{c}{ Female patients } \\
& Number & $\%$ & Number & $\%$ \\
\hline Total cases & 1058 & - & 702 & - \\
Tumoral cases & 427 & $40.4 \%$ & 249 & $35.5 \%$ \\
Malignant cases & 419 & $98.2 \%$ & 246 & $98.8 \%$ \\
Carcinoma cases & 374 & $89.3 \%$ & 199 & $80.9 \%$ \\
Adenocarcinoma cases & 167 & $44.7 \%$ & 108 & $54.3 \%$ \\
Squamous cell carcinoma cases & 101 & $27.0 \%$ & 31 & $15.6 \%$ \\
Small cell carcinoma cases & 48 & $12.8 \%$ & 28 & $14.1 \%$ \\
Large cell carcinoma cases & 33 & $8.8 \%$ & 13 & $6.5 \%$ \\
Adenosquamous carcinoma cases & 16 & $4.3 \%$ & 8 & $4.0 \%$ \\
Carcinoid cases & 6 & $1.6 \%$ & 9 & $4.5 \%$ \\
Salivary gland carcinoma cases & 3 & $0.8 \%$ & 2 & $1.0 \%$ \\
\hline
\end{tabular}

Table 1. Characteristics of Lung Carcinomas and Each Histological Subtype

\begin{tabular}{|c|c|c|c|c|c|c|}
\hline & $\begin{array}{c}\text { Number of } \\
\text { cases }\end{array}$ & Proportion & $\begin{array}{c}\text { Mean age } \\
\text { (years) }\end{array}$ & $\begin{array}{l}\text { Mean age in } \\
\text { male (years) }\end{array}$ & $\begin{array}{c}\text { Mean age in } \\
\text { female (years) }\end{array}$ & $\begin{array}{c}\text { Sex ratio } \\
\mathrm{M} / \mathrm{F}\end{array}$ \\
\hline Carcinomas & 573 & $100 \%$ & 64.8 & 65.1 & 64.3 & 1.9 \\
\hline Adenocarcinomas & 275 & $48.00 \%$ & 64.8 & 64.9 & 64.5 & 1.5 \\
\hline Squamous cell carcinomas & 132 & $23.00 \%$ & 66.7 & 66.5 & 67.5 & 3.3 \\
\hline Small cell carcinomas & 76 & $13.30 \%$ & 64.6 & 64.4 & 65 & 1.7 \\
\hline Large cell carcinomas & 46 & $8.00 \%$ & 64.2 & 64 & 64.8 & 2.5 \\
\hline Adenosquamous carcinomas & 24 & $4.20 \%$ & 69.3 & 70.4 & 67 & 2 \\
\hline Carcinoid tumours & 15 & $2.60 \%$ & 51.7 & 53.3 & 50.6 & 0.7 \\
\hline Salivary gland tumours & 5 & $0.90 \%$ & 45.4 & 49 & 40 & 1.5 \\
\hline
\end{tabular}

Table 3. Comparison of Lung Carcinoma Subtypes Proportion between Different Countries

\begin{tabular}{|c|c|c|c|c|c|c|c|}
\hline & \multirow[b]{2}{*}{ Lebanon } & \multirow{2}{*}{$\begin{array}{c}\text { North America } \\
\text { USA } \\
\text { (Houston } \\
\text { et al., 2014) }\end{array}$} & \multirow{2}{*}{$\begin{array}{l}\text { Europe } \\
\text { Norway } \\
\text { (Sagerup } \\
\text { et al., 2012) }\end{array}$} & \multirow{2}{*}{$\begin{array}{l}\text { Australia } \\
\text { Australia } \\
\text { (Mitchell } \\
\text { et al., 2013) }\end{array}$} & \multicolumn{3}{|c|}{ Asia } \\
\hline & & & & & $\begin{array}{c}\text { India } \\
\text { (Dey et al., } \\
\text { 2012) }\end{array}$ & $\begin{array}{c}\text { Iran } \\
\text { (Hajmanoochehri } \\
\text { et al., 2014) }\end{array}$ & $\begin{array}{l}\text { Japan } \\
\text { i } \quad \text { (Inoue } \\
\text { et al., 2014) }\end{array}$ \\
\hline & 2009-2014 & 2004-2009 & 2003-2007 & 2003 & 2006-2009 & 2001-2012 & 2004 \\
\hline Adenocarcinomas & $48.00 \%$ & $37.10 \%$ & $30.20 \%$ & $36.80 \%$ & $30.80 \%$ & $14.80 \%$ & $67.90 \%$ \\
\hline Squamous cell carcinomas & $23.00 \%$ & $21.90 \%$ & $20.60 \%$ & $20.10 \%$ & $35.10 \%$ & $52.70 \%$ & $22.30 \%$ \\
\hline Small cell carcinomas & $13.30 \%$ & $14.90 \%$ & $16.70 \%$ & $13.40 \%$ & $16.50 \%$ & $13.30 \%$ & $2.10 \%$ \\
\hline Large cell carcinomas & $8.00 \%$ & $3.20 \%$ & $3.80 \%$ & $10.80 \%$ & $5.90 \%$ & $6.40 \%$ & $3.30 \%$ \\
\hline Other carcinomas* & $7.70 \%$ & $22.90 \%$ & $28.70 \%$ & $18.90 \%$ & $11.70 \%$ & $12.80 \%$ & $4.40 \%$ \\
\hline
\end{tabular}

* Other carcinomas: adenosquamous carcinomas, carcinoid tumours, salivary gland tumours and carcinomas not otherwise specified

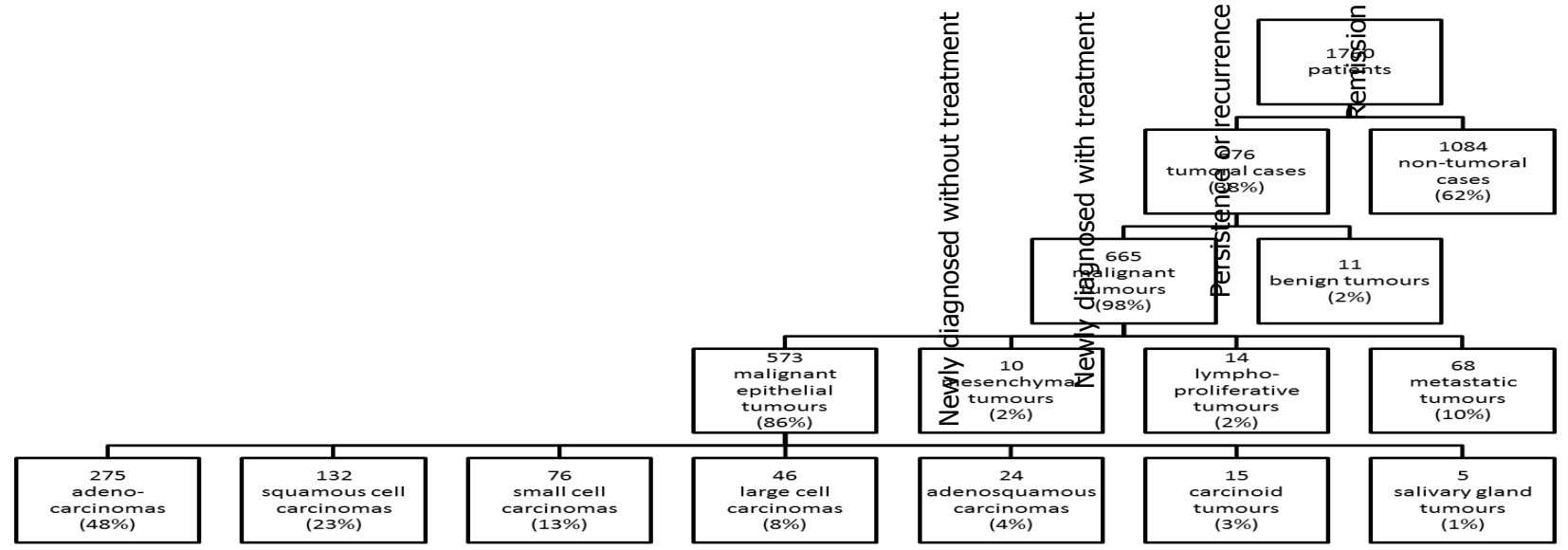

Figure 1. Distribution of the 1760 Patients According to Their Final Diagnosis 
$(8.0 \%)$ large cell carcinomas, $24(4.2 \%)$ adenosquamous carcinomas, $15(2.6 \%)$ carcinoid tumors and $5(0.9 \%)$ salivary gland tumors. The mean age of patients having adenocarcinoma was 64.8 years with an $\mathrm{M} / \mathrm{F}$ sex ratio of 1.5 ; the mean age in squamous cell carcinomas was 66.7 years with an $\mathrm{M} / \mathrm{F}$ sex ratio of 3.3 while the mean age in small cell lung carcinomas was 64.6 years with an $\mathrm{M} / \mathrm{F}$ sex ratio of 1.7 . The mean ages of patients with adenosquamous carcinomas and large cell carcinomas were consecutively 69.2 and 64.2 years with an $\mathrm{M} / \mathrm{F}$ sex ratio of 2.0 and 2.5 . The only $\mathrm{M} / \mathrm{F}$ sex ratio inferior to 1 (0.7) was that of carcinoid tumors, occurring at a mean age of 51.7 years. The salivary gland tumors had the lowest mean age of 45.5 years with an $\mathrm{M} / \mathrm{F}$ sex ratio of 1.5 . The mean age and $\mathrm{M} / \mathrm{F}$ sex ratio of each histologic subtype of lung carcinoma are summarized in table 1 .

A comparison of proportions between male and female patients is detailed in Table 2. In this series, the proportion of tumoral cases was slightly higher in male patients. However, within tumoral cases, both gender had approximately the same proportion of malignant tumors (over 98\%) and carcinomas (80-90\%). Within carcinoma subtypes, female patients had a higher proportion of adenocarcinomas at the expense of a lower squamous cell carcinoma proportion. The carcinoid proportion was almost three times higher in female than in male patients.

More than one third (210 cases; $36.6 \%$ ) of pulmonary carcinomas occurred in patients over the age of 70 years; only $1.7 \%$ of these carcinomas were in patients less than 40 years. Nearly $90 \%$ of adenosquamous carcinomas, more than $80 \%$ of squamous cell carcinomas, and two-thirds of small cell lung carcinomas and adenocarcinomas were diagnosed in patients over 60 years old. All the patients having salivary gland tumors and $60 \%$ of those having carcinoid tumors were diagnosed before the age of 60 .

\section{Discussion}

The mean age of patients diagnosed with epithelial malignant tumors in our population was 64.8 years, compared to 62 years for non-small cell lung carcinoma in China (Wang et al., 2014), and 65.2 years for all lung cancers in Kuwait (El-Basmy, 2013), 63.4 years for all lung carcinomas in Turkey (Demirci et al., 2013), 65.57 in Taiwan (Yang et al., 2013), 58 in India (Dey et al., 2012), 65 in France (Quoix and Lemarie, 2011) and 66.4 years in British Columbia, Canada (Yenugadhati et al., 2009). In Japan, 52.7\% of all lung cancers diagnosed in 2004 aged between 50 and 70 years (Inoue et al., 2014). In Norway, it is almost 70 years (Sagerup et al., 2012), while in Victoria (Australia), it reaches 72 years (Mitchell et al., 2013).

The $\mathrm{M} / \mathrm{F}$ sex ratio of lung cancer in our population was 1.9 , higher than lung cancer $\mathrm{M} / \mathrm{F}$ sex ratio in developed countries, which ranges between 1.3 in Canada (Yenugadhati et al., 2009) and 1.7 in Australia (Mitchell et al., 2013), Japan (Inoue et al., 2014), China (Wang et al., 2014) and United States (Lewis et al., 2014). Higher sex ratios have been reported in Asian countries such as 2.7 in Kuwait (El-Basmy, 2013), 4.1 in India (Dey et al., 2012) and 6.2 in Turkey (Demirci et al., 2013). This finding reflects probably smoking habits differences in women in developed countries as compared to those in developing countries.

On one hand, our study has the advantage of respecting the last WHO classification for lung tumors, while the majority of comparable published papers classified lung cancer in small cell and NSCLC in some papers and small cell/adenocarcinoma/squamous cell in others. On the other hand, this is also a limitation because of the difficulty to compare our data to that in the other papers. To counteract this limitation, we tried to standardize our data to be comparable by regrouping the lung cancer subtypes into small cell, adenocarcinoma, squamous cell carcinoma and others. A comparison of most frequent lung carcinoma subtypes with other countries is available in Table 3 .

Adenocarcinoma turned out to be the most frequent lung carcinoma in our study, with $48 \%$ of all carcinomas, $41 \%$ of all malignant tumors, $41 \%$ of all tumors and $16 \%$ of all patients investigated. It also represented the most frequent lung carcinoma in each gender, accounting for $45 \%$ of all men carcinomas and $54 \%$ of all women carcinomas. Smoking is known to be a risk factor for lung cancer and especially for squamous cell carcinoma. A meta-analysis of all papers published from 1900 to 2000, showed a Relative Risk of 10.47 for squamous cell carcinoma, compared to 5.50 for all lung cancer and 2.84 for adenocarcinoma (Lee et al., 2012). However, a recent international study reevaluated smoking habits and revealed three factors explaining the recent increase in lung adenocarcinoma (Lortet-Tieulent et al., 2014). First of all, the increased consumption of filtered lower tar- and nicotine-containing cigarettes induces a deeper inhalation and a more peripheral distribution of smoke in the lung. Second, longer smoking durations allow the development of adenocarcinomas later than squamous cell carcinomas. Finally, the risk of developing an adenocarcinoma after smoking cessation decreases less rapidly than for squamous cell carcinoma and small cell carcinoma (Lortet-Tieulent et al., 2014).

Squamous cell carcinoma of the lung was the second most frequent histological subtype representing $23 \%$ of all lung carcinomas in Lebanon. Similar rates ranging between 20 and $25 \%$ have been reported in the United States (Lewis et al., 2014), Japan (Inoue et al., 2014), Norway (Sagerup et al., 2012) and Australia (Mitchell et al., 2013). This proportion is much higher in some Asian countries: $35.1 \%$ in India (Dey et al., 2012) and $47.2 \%$ in Turkey (Demirci et al., 2013). This can be explained by the shift in the histologic subtypes of lung carcinoma from squamous to adenocarcinomas in the developed countries due to probable environmental and lifestyle modifications, while this shift hasn't been observed in the developing countries. This shift has been previously confirmed in the United States and in China over the past few decades (Kong et al., 2014; Lewis et al., 2014).

Small cell carcinoma constituted approximately $13 \%$ of all epithelial malignant tumors of the lung. Similar proportions have been reported: $13.2 \%$ to $14.9 \%$ in the United States (Houston et al., 2014; Lewis et al., 2014), $13.3 \%$ in Iran (Hajmanoochehri et al., 2014), 13.4\% in Australia (Houston et al., 2014) and $13.7 \%$ in Taiwan (Yang et al., 2013). The proportion of small cell carcinoma 


\section{Hampig Raphael Kourie et al}

decreases to $10 \%$ in Kuwait (El-Basmy, 2013) and Canada (Yenugadhati et al., 2009), and exceeds 15\% in India (Dey et al., 2012), Norway (Sagerup et al., 2012) and Turkey (Demirci et al., 2013).

In conclusion, During a five year period, 1760 specimens of lung cancer were analyzed and 676 tumors were diagnosed. We reviewed at our institution the histologic distribution of lung tumors according to the 2004 WHO classification subtypes, aiming to reflect the national lung cancer characteristics. From 573 malignant epithelial tumors, adenocarcinomas turned out to be the most frequent lung carcinoma in our study with $48 \%$. Squamous lung cancers represented $23 \%$ and small cell lung cancer $13 \%$ of all malignant epithelial tumors. This histologic repartition of lung tumors in Lebanon is similar to that in developed countries. We believe this resemblance is due to common smoking habits, known to be responsible for the increase of lung adenocarcinoma at the expense of other subtypes.

\section{References}

Demirci E, Daloglu F, Gundogdu C, et al (2013). Incidence and clinicopathologic features of primary lung cancer: a NorthEastern Anatolia region study in Turkey (2006-2012). Asian Pac J Cancer Prev, 14, 1989-93.

Dey A, Biswas D, Saha SK, et al (2012). Comparison study of clinicoradiological profile of primary lung cancer cases: an Eastern India experience. Indian J Cancer, 49, 89-95.

El-Basmy A (2013). Profile of lung cancer in kuwait. Asian Pac $J$ Cancer Prev, 14, 6181-4.

Ferlay J, Soerjomataram I, Dikshit R, et al (2015). Cancer incidence and mortality worldwide: sources, methods and major patterns in GLOBOCAN 2012. Int J Cancer, 136, 359-86.

Hainsworth JD, Fang L, Huang JE, et al (2011). BRIDGE: an open-label phase II trial evaluating the safety of bevacizumab + carboplatin/paclitaxel as first-line treatment for patients with advanced, previously untreated, squamous non-small cell lung cancer. J Thorac Oncol, 6, 109-14.

Hajmanoochehri F, Mohammadi N, Zohal MA, et al (2014). Epidemiological and clinicopathological characteristics of lung cancer in a teaching hospital in Iran. Asian Pac J Cancer Prev, 15, 2495-500.

Houston KA, Henley SJ, Li J, et al (2014). Patterns in lung cancer incidence rates and trends by histologic type in the United States, 2004-2009. Lung Cancer, 86, 22-8.

Inoue M, Okumura M, Sawabata N, et al (2014). Clinicopathological characteristics and surgical results of lung cancer patients aged up to 50 years: the Japanese Lung Cancer Registry Study 2004. Lung Cancer, 83, 246-51.

Kong J, Xu F, He M, et al (2014). The incidence of lung cancer by histological type: a population-based study in Tianjin, China during 1981-2005. Respirol, 19, 1222-8.

Lee PN, Forey BA, Coombs KJ (2012). Systematic review with meta-analysis of the epidemiological evidence in the 1900s relating smoking to lung cancer. BMC Cancer, 12, 385.

Lewis DR, Check DP, Caporaso NE, et al (2014). US lung cancer trends by histologic type. Cancer, 120, 2883-92.

Lortet-Tieulent J, Soerjomataram I, Ferlay J, et al (2014). International trends in lung cancer incidence by histological subtype: adenocarcinoma stabilizing in men but still increasing in women. Lung Cancer, 84, 13-22.

Mitchell PL, Thursfield VJ, Ball DL, et al (2013). Lung cancer in Victoria: are we making progress? Med J Aust, 199, 674-9.
National Cancer Registry [Online] (2008). Beirut: Ministry of Public Health.

Quoix E, Lemarie E (2011). [Epidemiological novelties in lung cancer]. Rev Mal Respir, 28, 1048-58.

Sagerup CM, Smastuen M, Johannesen TB, et al (2012). Increasing age and carcinoma not otherwise specified: a 20 -year population study of 40,118 lung cancer patients. $J$ Thorac Oncol, 7, 57-63.

Scagliotti GV, Parikh P, von Pawel J, et al (2008). Phase III study comparing cisplatin plus gemcitabine with cisplatin plus pemetrexed in chemotherapy-naive patients with advancedstage non-small-cell lung cancer. J Clin Oncol, 26, 3543-51.

Spitz MR, Gorlov IP, Amos CI, et al (2011). Variants in inflammation genes are implicated in risk of lung cancer in never smokers exposed to second-hand smoke. Cancer Discov, 1, 420-9.

Wang J, Wu N, Zheng Q, et al (2014). Evaluation of the 7th edition of the TNM classification for lung cancer at a single institution. J Cancer Res Clin Oncol, 140, 1189-95.

Yang P (2011). Lung cancer in never smokers. Semin Respir Crit Care Med, 32, 10-21.

Yang SC, Lai WW, Su WC, et al (2013). Estimating the lifelong health impact and financial burdens of different types of lung cancer. BMC Cancer, 13, 579.

Yenugadhati N, Birkett NJ, Momoli F, et al (2009). Occupations and lung cancer: a population-based case-control study in British Columbia. J Toxicol Environ Health A, 72, 658-75. 